\title{
Luc Racine
}

Sociologue, Département de sociologie, Université de Montréal

\author{
(1967)
}

\section{"Dépossession et domination. Présentation.”}

Un document produit en version numérique par Jean-Marie Tremblay, bénévole, professeur de sociologie au Cégep de Chicoutimi

Courriel: jean-marie_tremblay@uqac.ca

Site web pédagogique : http://www.uqac.ca/jmt-sociologue/

Dans le cadre de: "Les classiques des sciences sociales" Une bibliothèque numérique fondée et dirigée par Jean-Marie Tremblay, professeur de sociologie au Cégep de Chicoutimi

Site web: http://classiques.uqac.ca/

Une collection développée en collaboration avec la Bibliothèque Paul-Émile-Boulet de l'Université du Québec à Chicoutimi Site web: http://bibliotheque.uqac.ca/ 


\section{Politique d'utilisation de la bibliothèque des Classiques}

Toute reproduction et rediffusion de nos fichiers est interdite, même avec la mention de leur provenance, sans l'autorisation formelle, écrite, du fondateur des Classiques des sciences sociales, Jean-Marie Tremblay, sociologue.

Les fichiers des Classiques des sciences sociales ne peuvent sans autorisation formelle:

- être hébergés (en fichier ou page web, en totalité ou en partie) sur un serveur autre que celui des Classiques.

- servir de base de travail à un autre fichier modifié ensuite par tout autre moyen (couleur, police, mise en page, extraits, support, etc...),

Les fichiers (.html, .doc, .pdf, .rtf, .jpg, .gif) disponibles sur le site Les Classiques des sciences sociales sont la propriété des Classiques des sciences sociales, un organisme à but non lucratif composé exclusivement de bénévoles.

Ils sont disponibles pour une utilisation intellectuelle et personnelle et, en aucun cas, commerciale. Toute utilisation à des fins commerciales des fichiers sur ce site est strictement interdite et toute rediffusion est également strictement interdite.

L'accès à notre travail est libre et gratuit à tous les utilisateurs. C'est notre mission.

Jean-Marie Tremblay, sociologue

Fondateur et Président-directeur général, LES CLASSIQUES DES SCIENCES SOCIALES. 
Cette édition électronique a été réalisée par Jean-Marie Tremblay, bénévole, professeur de sociologie au Cégep de Chicoutimi à partir de :

Luc Racine

Sociologue, Département de sociologie, Université de Montréal

"Dépossession et domination. Présentation.”

Un article publié dans la revue Parti pris, revue politique et culturelle, vol. 4, nos 9-12, mai-août 1967, pp. 7-10.

Les ayant-droit de l'œuvre de M. Luc Racine, sociologue, professeur au département de sociologie de l’Université de Montréal, nous a accordé le 9 septembre 2011 leur autorisation de diffuser la totalité des publications de l'auteur dans Les Classiques des sciences sociales.

Polices de caractères utilisée :

Pour le texte: Times New Roman, 14 points.

Pour les citations : Times New Roman, 12 points.

Pour les notes de bas de page : Times New Roman, 12 points.

Édition électronique réalisée avec le traitement de textes Microsoft Word 2008 pour Macintosh.

Mise en page sur papier format : LETTRE US, 8.5'” x 11',

Édition numérique réalisée le 20 octobre 2012 à Chicoutimi, Ville de Saguenay, Québec.

\section{Fait avec}

Macintosh 


\author{
Luc Racine
}

Sociologue, Département de sociologie, Université de Montréal

\title{
"Dépossession et domination. Présentation”
}

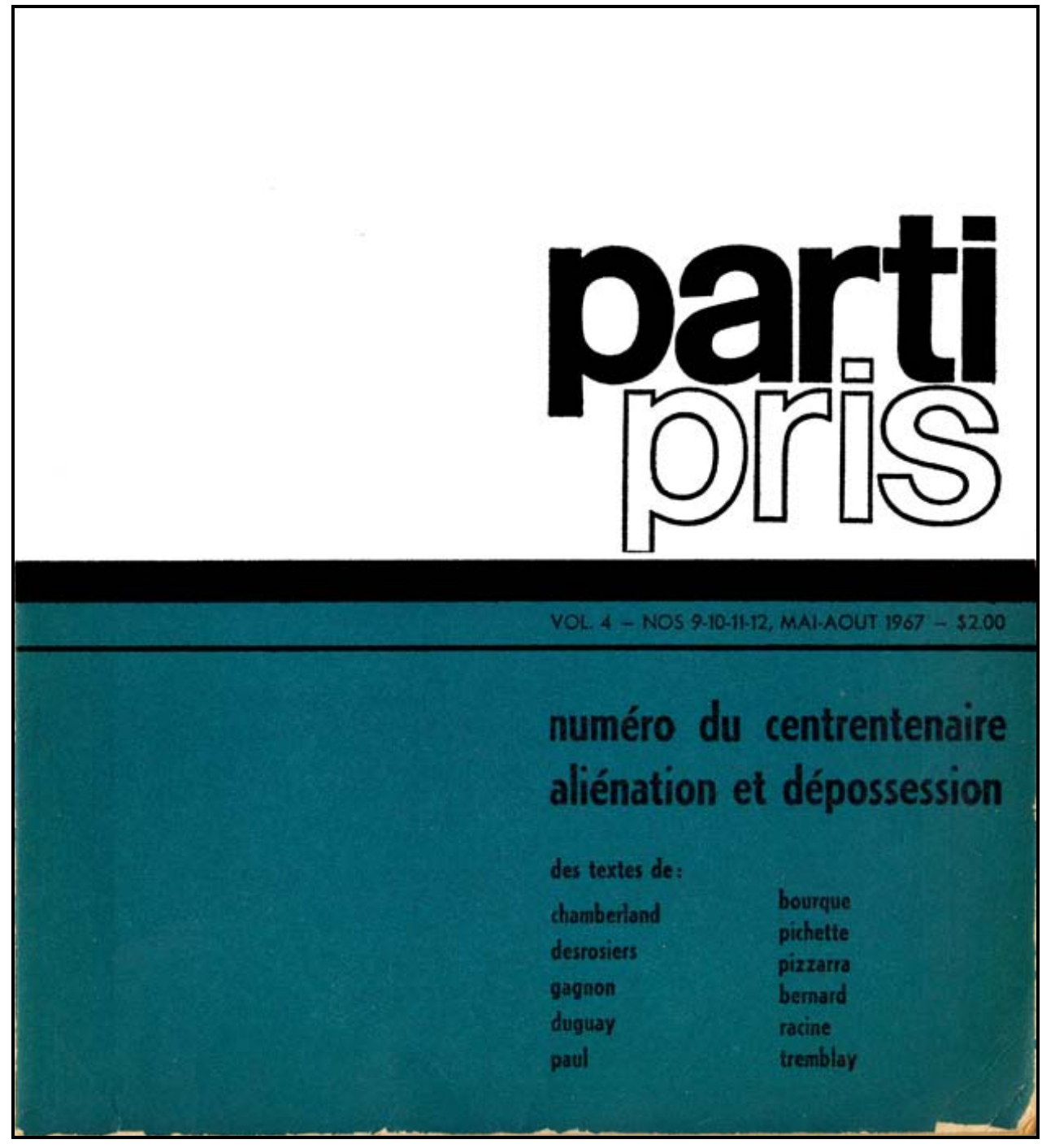

Un article publié dans la revue Parti pris, revue politique et culturelle, vol. 4, nos 9-12, mai-août 1967, pp. 7-10. 
Luc Racine

Sociologue, Département de sociologie, Université de Montréal

"Dépossession et domination. Présentation.”

Un article publié dans la revue Parti pris, revue politique et culturelle, vol. 4, nos 9-12, mai-août 1967, pp. 7-10.

... poème en laisse, pour la dernière fois la m'apitoie, sur toi, avec nos deux siècles de saule pleureur dans la voix.

Gaston Miron

Ce numéro n'est pas le premier que nous consacrons à l'analyse de la culture québécoise et il est fort probable que nous ayons encore à revenir quelques fois sur ce thème. Aujourd'hui encore, l'immonde mystification que représente l'Expo 67 est là pour ramener a notre mémoire, si besoin en est, toute la dépossession qui est notre lot le plus quotidien - sur la Terre des Hommes nous ne sommes rien ou presque, quantité négligeable, sous-hommes plus ou moins bien nantis à la marge d'un empire dont tous les pouvoirs de destruction et de massacre ne se sont sans doute pas encore pleinement manifestés.

Cette fois, cependant, nous ne parlerons pas beaucoup en termes de dépossession et d'aliénation culturelle, de colonisation ou de décolonisation : non pas parce que nous ne croyons plus que le Québec soit globalement dominé par les U.S.A. et leur satellite [8] anglo-canadien mais plutôt parce que, refaisant graduellement le chemin qui a mené Marx de l'humanisme des Manuscrits économico-philosophiques aux analyses scientifiques du Capital, nous apprenons maintenant à parler clair, à démonter péniblement les mécanismes socio-économiques 
d'une domination totale, à expliquer notre mal enfin après l'avoir nommé.

Ainsi, la plupart des articles composant ce numéro s'inspirent plus ou moins de la méthode propre à une analyse marxiste de la culture. De cette façon, nous avons voulu élaborer, en tirant parti le plus pleinement possible des travaux d'hommes comme Mehring, Goldmann, Lukàcs, Marcuse, Althusser et Macherey, une approche vraiment rigoureuse des diverses manifestations culturelles de notre société, de la poésie à l'interprétation de l'histoire et à l'idéologie politique. Le travail réalisé ici n'est qu'une première étape de l'étude systématique de la culture québécoise, étude systématique qui, à notre avis, constitue l'un des meilleurs outils pouvant servir à l'élaboration d'une politique planifiée pour la pratique socialiste sur le plan théorique, scientifique, artistique, littéraire, poétique, etc....

Sur le plan poétique, Paul Chamberland, par une analyse de la thématique des poètes québécois, de Granbois à Brault, montre les relations complexes entre la vision du monde de certains parmi nos poètes, les plus importants et la situation des principaux groupes sociaux qui se manifestèrent lors de la Révolution tranquille : il se dégage en outre de son étude que la problématique de ces groupes, sur le plan culturel, est en voie d'être dépassée ; l'échec de la Révolution tranquille marque ainsi la nécessité d'un renouvellement qui ne soit pas exclusivement politique, mais aussi socio-économique et culturel.

De la même façon, en mettant à jour les contradictions de la pensée politique d'Henri Bourassa et en les rattachant à la situation de la bourgeoisie libérale entre les années 1900-1939, Pierre Desrosiers nous montre à quel point, historiquement, cette classe fut toujours incapable de résoudre, que ce soit sur le plan politico-économique ou idéologique, les problèmes divers liés à la domination de la société et de la culture québécoise par le monde anglo-saxon. C'est aussi dans cette optique qu'il faut lire l'inestimable contribution de Charles Gagnon, aujourd'hui emprisonné, sur l'étude des classes sociales au Québec lors de l'Insurrection 1837-38 : là encore, on constate l'impossibilité profonde de la bourgeoisie des professions libérales à représenter vraiment les intérêts essentiels du Québec dans le domaine politique et économique. 
À un autre niveau, l'article de Raoul Duguay et d'Andrée Paul nous [9] montre comment la désorganisation de la vie culturelle, pour ce qui est des beaux-arts autant que pour ce qui est du cinéma et de la musique, s'explique par l'emprise des monopoles américains sur le marché québécois et par l'absence de toute politique culturelle cohérente de la part d'un gouvernement inepte, ayant représenté jadis des intérêts déjà plutôt restreints et symbolisant aujourd'hui l'ultime point de décadence et le caractère néfaste d'un clergé réactionnaire allié à des professionnels aussi incompétents que malhonnêtes. C'est dans cette perspective que G. Bourque, M. Pichette, N. Pizarro et L. Racine proposent, dans leur article consacré à la production culturelle et aux classes sociales, un rapprochement entre les producteurs culturels et les syndicats afin de rendre graduellement possible la représentation par un parti socialiste, encore à créer sur la base que constitue le mouvement syndical, des besoins culturels de la majorité de la population. Parallèlement à cela, Philippe Bernard et Gaëtan Tremblay, à partir d'une étude de la spécificité culturelle et sociale du Québec traditionnel, entreprennent d'illustrer comment certaines caractéristiques dominantes de la personnalité collective des Québécois, tels l'égalitarisme, la solidarité et le mode de libération de l'agressivité, pourraient être des facteurs positifs dans la lutte pour le socialisme. À la suite de cela, il ressort clairement qu'il est indispensable, dans une perspective socialiste et décolonisatrice, de faire servir l'analyse de la culture et de ses relations avec l'ensemble de la vie socio-économique à l'élaboration d'une politique cohérente qu'un parti socialiste encore à venir pourrait opposer à la politique morcelée des partis en place et, une fois au pouvoir, appliquer dans l'intérêt du développement non seulement économique mais aussi culturel de tous les travailleurs québécois.

Et enfin, en lisant le texte de Camil Guy, on pourra voir jouer, dans le cas des Indiens du Québec, le même phénomène de prolétarisation et de désagrégation culturelle ayant également marqué, au commencement du siècle, le passage du Québec d'une société rurale à une société industrielle entièrement déterminée de l'extérieur par les décisions politiques et économiques des grandes compagnies américaines. La dialectique de la domination et de la dépossession socioéconomiques et culturelles s'articule ainsi sur un axe qui va de l'american way of life à la décadence de la culture indienne, par l'intermé- 
diaire du train de la Confédération et de la parade de la Saint-Jean Baptiste.

Comme il se dégage des principaux articles de ce numéro, notre culture reste à faire, la bourgeoisie québécoise a été foncièrement incapable d'assurer [10] un développement culturel véritable, cette impuissance à produire une culture valable étant d'ailleurs indissociable d'une même incapacité à contrôler le développement socioéconomique. Et, puisque la production et la diffusion de la culture sont, au Québec, sous le contrôle des monopoles anglo-canadiens ou américains, une prochaine étape de notre travail devra évidemment consister en l'étude détaillée des modalités de ce contrôle par l'intermédiaire des divers moyens de communication de masse, telles la radio, la télévision, la presse, etc. Pour que la culture québécoise puisse se développer selon les besoins de tous les travailleurs, il faudra nécessairement qu'un jour soient prises, par un parti qui les représentera, l'ensemble des mesures permettant de faire de l'information et de l'éducation les outils d'une politique culturelle adéquate. Toutefois, la reprise du contrôle de l'éducation et de l'information est liée à la reprise du contrôle des secteurs-clefs de notre économie : l'analyse de la production culturelle renvoie ainsi à l'analyse de la domination économique et aux moyens politiques d'en rompre le cercle où nous avons erré tous les siècles de notre histoire.

Fin du texte 